\title{
La interpretación constitucional: entre legicentrismo, neoconstitucionalismo y constitucionalización*
}

\author{
Constitutional interpretation: between \\ legicentrism, neoconstitutionalism and \\ constitutionalisation
}

Joaquín Acosta Rodríguez ${ }^{* *}$

\begin{abstract}
RESUMEN
La presentación de la ley como la expresión de la voluntad general hoy exige corrección. La ley es en adelante cuestionable también por razones de fondo, a la luz de los principios y valores constitucionales, a despecho de la concepción positivista. En consecuencia, el juez constitucional generalmente disfruta de un papel considerable en materia de interpretación de la Constitución, e incide en la interpretación del resto de normas jurídicas. Es él quien da todo su sentido al texto constitucional insuflándole vida. En vista de la nueva realidad, se le reprocha ir demasiado lejos, al punto de imponer su propia visión de la realidad, desplazando asi la voluntad del constituyente. De hecho, la constitucionalización ha sido objeto de estigmas. En el fondo, buena parte de las criticas y temores son resultado de malentendidos o posiciones extremadamente radicales.
\end{abstract}

PALABRAS CLAVE: Legalismo, legicentrismo, constitucionalismo, neoconstitucionalismo, constitucionalización, positivismo, postpositivismo, tercera vía.

\begin{abstract}
The presentation of the law as the expression of general will today, requires correction; the law is questionable for reasons of substance, in light of constitutional principles and values, in defiance of the positivist conception. Consequently, the constitutional judge usually enjoys a considerable role in the interpretation of the Constitution, thus affecting interpretation of other legal norms. It is he who gives full meaning to the constitutional text, giving it life. Of course, in light of the new reality, he is criticized for going too far, to the point of imposing his own vision of reality; thus, displacing the will of the constituent assembly. In fact the constitutionalisation has been the subject of stigmas. In the background, many of the criticisms and fears are the result of misunderstandings or extremely radical positions.
\end{abstract}

KEY WORDS: Legalism, legicentrism, constitutionalism, neoconstitutionalism, constitutionalisation, positivism, postpositivism, third way.

\footnotetext{
* Recibido: 2 de agosto de 2015. Aceptado: 8 de septiembre de 2015.

** Profesor en la Facultad de Derecho y Ciencias Politicas de la Universidad de La Sabana, Bogotá, Colombia. (joaquinacosta2001@yahoo.fr)
} 


\section{SUMARIO}

1. Introducción

2. Del control de constitucionalidad de las leyes a la constitucionalización del derecho

3. Del constitucionalismo al neoconstitucionalismo

4. Del aporte kelseniano al derecho constitucional

5. El positivismo

6. La experiencia de Austria

7. La experiencia de la República de Weimar

8. La constitucionalización del derecho: una secuela de posguerra

9. Más allá del iusnaturalismo y del iuspositivismo

10. El principio de constitucionalidad

11. Conclusión

\section{Introducción}

Actualmente, no sólo la interpretación constitucional, sino la de todo el derecho están marcadas por la constitucionalización. La constitucionalización del orden jurídico ha sido principalmente descrita en Francia por Favoreu, quien desde 1980 invitó a los juristas de su país a reconocer que "lo constitucional está 'coloreando' progresivamente la totalidad de ramas del derecho" y más ampliamente al orden jurídico entero. Demostró que la jurisprudencia del Conseil constitutionnel se convirtió en un referente ineludible, no solamente de la vida política sino también del orden jurídico. ${ }^{1}$ De esta manera, "es necesario admitir que el derecho constitucional irriga tanto al derecho público como al derecho privado". ${ }^{2}$

La comunidad de juristas europeos perciben así la realidad de este fenómeno, y no solamente los iuspublicistas. Reconocen que la constitucionalización de un derecho o libertad ejerce una profunda influencia sobre todo el ordenamiento jurídico. ${ }^{3}$ Desde entonces, el "reflejo constitucional" de los sistemas jurídicos influenciados por las construcciones europeas indudablemente se ha desarrollado, acelerando particularmente el fenómeno de

\footnotetext{
${ }^{1}$ Hourouebie, FabricE. Le pouvoir juridictionnel en France, LGDJ, Paris, 2010.

2 II faut admettre que le droit constitutionnel irrigue tant le droit public que le droit privé. Molfessis, Nicolas. "Le Conseil constitutionnel et le droit privé", No. 9, LGDJ, Paris, 1998, p. 10.

${ }^{3}$ Fromont, Michelle. "Les droits fondamentaux dans I'ordre juridique de la République Fédérale d'Allemagne", Recueil d'Études en Hommage à Charles Eisenmann, Cujas, Paris, 1974, p. 49.
} 
constitucionalización del orden jurídico. ${ }^{4}$ Es en tal contexto que la investigación tendrá presente determinadas teorías de posguerra, las cuales han contribuido a la consagración de las constituciones políticas, en tanto que auténticas normas jurídicas.

\section{Del control de constitucionalidad de las leyes a la constitucionalización del derecho}

La tradición jurídica francesa ha manifestado grandes reticencias hacia el control de constitucionalidad de las leyes. Ello se debe a las críticas que preconizan que tanto la ley ordinaria como la norma constitucional son el trabajo de asambleas elegidas y por ende representativas del pueblo. De tal manera, expresan la voluntad general. En esas condiciones, las reglas más antiguas corresponden a una voluntad superada de la nación; las segundas, a su voluntad actual. ${ }^{5}$ En realidad tal planteamiento constituye un sofisma que desconoce la jerarquía de las normas jurídicas: en efecto, sería ilógico que el gobierno esté sometido a un control judicial cuando profiere actos administrativos -también de carácter general- y que por el contrario escape a tales medidas cuando se dedica a impulsar la aprobación parlamentaria de leyes. ${ }^{6}$

Legalidad y legitimidad jurídicas representan dos nociones claramente diferentes, que pertenecen a categorias netamente separadas. La legalidad designa el efecto coercitivo inherente a las normas legales, cuyo respeto está asegurado por los poderes públicos bajo pena de sanción. La legitimidad es la calidad de un poder cuya ideología, las fuentes de inspiración y los criterios de referencia son objeto de adhesión si no unánime, al menos sí mayoritaria por parte de los gobernados. En otros términos, entre legalidad y legitimidad hay una diferencia de naturaleza o clase, y no de grado. Es eminentemente deseable que el orden constitucional positivo sea legítimo, esto es, conforme al sentimiento popular y aceptado por un amplio consenso. ${ }^{7}$ En aras de garantizar tal sentimiento, se ha instituido un control para velar por el respeto de las normas superiores de sus homólogas inferiores. De esta manera, si una regla inferior transgrede una regla superior, aquella deberá ser anulada. ${ }^{8}$

\footnotetext{
${ }^{4}$ Favoreu, Louis, "La constitutionnalisation du droit", Mélanges R. Drago, Economica, Paris, 1996, p. 35.

${ }^{5}$ Pactet, Pierre, Méln-Soucramanien, Ferdinand, Droit constitutionnel, Sirey, Paris, 2013, p. 70.

${ }^{6}$ lbid.

7 Ibidem, p. 63; Adde, Schmitt, (Carl., "Legalidad y legitimidad", Madrid, 1971.

${ }^{8}$ Favoreu, Louis. "Actualité et légitimité du contrôle juridictionnel des lois en Europe occidentale", RDP, France, 1984, p. 1147.
} 


\section{Del constitucionalismo al neoconstitucionalismo ${ }^{9}$}

Si el constitucionalismo es una doctrina que procura la generalización del fenómeno constitucional, es decir, la adopción de constituciones escritas en aras de institucionalizar el poder político, ${ }^{10}$ el neoconstitucionalismo es una doctrina que no sólo pretende institucionalizar el poder, sino además erigir la Constitución como una auténtica norma jurídica, ${ }^{11}$ superior a las otras disposiciones del orden jurídico ${ }^{12}$ con el fin de evitar la concentración del poder en los representantes del pueblo. Esta visión implica así la idea de la necesidad de un control de constitucionalidad de las leyes de tal manera que se conserve el carácter de norma obligatoria de la Constitución. ${ }^{13}$ Esta superioridad jerárquica reposa sobre bases a la vez formales y substanciales, ya que la Constitución contiene un conjunto de principios que son la conditio sine qua non de los derechos fundamentales de los individuos. ${ }^{14}$

Así se justifica la sumisión de los órganos políticos e incluso particulares al texto constitucional, especialmente a través de la instauración de un juez constitucional; de esta manera, se pone fin al dogma rousseauniano del absolutisme législatif. ${ }^{15}$ Es por ello que el neoconstitucionalismo no sólo pretende el proceso que conduce a la elaboración de una Constitución, sino también que tal texto materialice el establecimiento de un Estado de derecho constitucional. En consecuencia, la constitucionalización es la realización de un sistema jurídico que se produce y se reproduce desde la norma constitucional. ${ }^{16}$ De esta manera, una rama del derecho está consti-

\footnotetext{
9 "El marco teórico que ha dado origen a la mayoría de las discusiones en torno a la constitucionalización del derecho (no sólo en el área del privado), es el del neoconstitucionalismo". Espinosa, Beatriz y Escobar, LINA. "Neoconstitucionalismo y derecho privado: el debate", Diké, Bogotá, 2008, p. 16.

${ }^{10}$ Guastinı, Riccardo. Leçons de théorie constitutionnelle, Dalloz, Paris, 2010, p. 163.

${ }^{11}$ Los líderes de esta corriente de pensamiento son Robert Alexy, Ronald Dworkin, Luigi Ferrajoli, Jürgen Habermas, Carlos Nino y Gustavo Zagrebelsky. Véase BRunet, PieRre. "Remarques critiques sur le constitutionnalisme contemporain", Droit et économie. Interférences et interactions. Etudes en I'honneur du Professeur Michel Bazex, Litec, Paris, 2009, p. 51.

${ }^{12}$ Brunet, PierRe. Remarques critiques sur le constitutionalisme contemporain, Droit et économie. Interférences et interactions. Etudes en I'honneur du Professeur Michel Bazex, Litec, París, 2009, p. 55.

${ }^{13}$ Véase Troper, Michel. "Constitution", en Arnaud, André-Jean (Dir.), Dictionnaire encyclopédique de théorie et de sociologie du droit, LGDJ, París, 1993, p. 104.

${ }^{14}$ Desmons, Éric. "Le divan des Nomophobes : Sade et Saint-Just chez Deleuze", en Puigeller, Catherine (Dir.), La loi. Bilan et perspective, Economica, París, 2005, p. 294.

${ }^{15}$ Mouton, Stéphane. "La constitutionnalisation du droit en France. Rationalisation du pouvoir et production normative", Thèse Toulouse I, France, 1998, p. 17.

${ }^{16}$ El sufijo -zación conlleva entonces una ambivalencia al designar tanto un estado como el proceso que conduce a tal estado: el establecimiento del Estado constitucional. Véase Ruiz Fabri, Héléne y Grewe, Constance. "La constitutionnalisation à l'épreuve du droit international et du droit européen", en Les dynamiques du droit européen en début de siècle. Études en l'honneur de Jean-Claude Gautron, Pédone, París, 2004, p. 191.
} 
tucionalizada cuando su elaboración y su contenido son conformes con el texto constitucional. ${ }^{17}$

De esta manera, el neoconstitucionalismo ha retirado todo carácter sagrado a la ley, al punto de haber reemplazado el Código por la Constitución en el orden jurídico. ${ }^{18}$ Así, se conduce el derecho alrededor de un nuevo eje: ${ }^{19}$ la defensa de la superioridad normativa de la Constitución. Francia no es la única nación europea en tal situación. Otros países de tradición romanista, a semejanza de Alemania, han constatado igualmente este cambio de paradigma entre el Código y la Constitución. ${ }^{20}$ Esto significa que los fundamentos mismos del derecho se han desplazado del Código hacia principios superiores. ${ }^{21}$ Además, la adopción de una Constitución con posterioridad a los códigos generalmente acelera el ritmo de producción de las normas especiales, ubicadas por fuera de los códigos. En efecto, un nuevo texto constitucional conlleva un nuevo proyecto de sociedad, el cual no se compadece necesariamente con los códigos anteriores. Los paradigmas conocidos por la codificación se han vuelto caducos. ${ }^{22}$

América Latina tiende a adoptar un sistema de control concentrado de constitucionalidad, influenciado por el modelo europeo. ${ }^{23}$ Es por ello que resulta conveniente explorar el esquema europeo de justicia constitucional. El advenimiento de este sistema de justicia en Europa se presenta como la culminación histórica de una lenta evolución de las ideas y del concepto mismo de democracia. Producto de las concepciones de la escuela del derecho natural desde la filosofía clásica griega a Santo Tomás, Grocio o Puffendorf, la idea de un derecho superior se difunde al principio en Europa. Sin embargo, esta corriente se verá desafiada por el positivismo, el cual alcanzará en el ámbito continental su auge gracias a Hans Kelsen.

\section{Del aporte kelseniano al derecho constitucional}

El positivismo constitucional kelseniano consagra, a partir de la teoría de la construcción del derecho por grados, la exigencia de un control de constitucionalidad,

\footnotetext{
${ }^{17}$ Zoller, Élizabeth. "Le Code civil et la Constitution", en Le Code civil 1804-2004, un passé, un présent, un avenir, Dalloz, Paris, 2004, p. 975.

${ }^{18}$ Cerda-Guzman, Carolina. "Codification et constitutionnalisation", lgdj, Paris, 2011, No. 39, p. 31.

${ }^{19}$ Favoreu, Louls., "Légalité et constitutionnalité", Les Cahiers du Conseil constitutionnel, No. 3, France, 1997, p. 73.

${ }^{20}$ Cerda-Guzman, Carolina. Op. cit., p. 32.

${ }^{21}$ Rémy, Pнiцlıе. "Le processus de 'dé-codification'", en Le Code civil français dans le droit européen, Actes du colloque sur le bicentenaire du Code civil français organisé à Genève les 26-28 février 2004, Bruylant, Bruxelles, 2005, p. 213. ${ }^{22}$ Cerda-Guzman, Carolina. Op. cit., p. 32.

${ }^{23}$ Villabella, Carlos Manuel. Nuevo constitucionalismo latinoamericano ¿un nuevo paradigma? Mariel, México, 2014, p. 17.
} 
ejercido por una jurisdicción única, en aras de garantizar el principio de la jerarquía de las normas y la coherencia del orden jurídico. En efecto, mal se podría contar con un exclusivo autocontrol del parlamento mismo para garantizar su subordinación a la Constitución. ${ }^{24}$ Según Kelsen, el control de constitucionalidad ante todo debe estar centralizado, es decir, debe ejercerlo una jurisdicción constitucional específica. Por ende, tal control no ha de estar confiado a los jueces ordinarios, como en Estados Unidos. ${ }^{25} \mathrm{La}$ ausencia de la regla del precedente en los sistemas romano-germánicos multiplica los riesgos de contradicción de la jurisprudencia, e impediría por ello la materialización de una interpretación común a la totalidad de jurisdicciones. Solamente una Corte Constitucional única, competente para pronunciar la anulación de una norma contraria a la Constitución, puede garantizar la coherencia del ordenamiento jurídico a través del respeto, por parte del resto de tribunales, de la interpretación constitucional. ${ }^{26}$ Así, tal juez será ante todo un legislador negativo cuya actividad estará absolutamente determinada por la Constitución. El modelo kelseniano se expandiría al comienzo en el contexto austriaco y posteriormente, y de manera progresiva, en Europa continental, debido al auge del positivismo jurídico.

\section{El positivismo}

En principio una ciencia describe, no prescribe: constata lo que es, sin crear nada. ${ }^{27}$ Bajo esta lógica, el positivismo designa una postura teórica que ante todo rechaza cualquier metafísica jurídica y toda idea de derecho natural. ${ }^{28}$ Es por ello que los miembros de la doctrina denominada positivista se pretenden los únicos conocedores de la realidad positiva, jurídica o científica. ${ }^{29}$ El positivismo no reconoce más derecho que aquel que es puesto, impuesto por el poder político. ${ }^{30}$ Esta doctrina puede presentarse bajo diversas formas, una de ellas es la del normativismo, teoría desarrollada por Hans Kelsen y basada en la idea según la cual el derecho es un sistema de normas jurídicas que regula la conducta de los seres humanos. ${ }^{31}$

${ }^{24}$ Favoreau, Louis. Droit constitutionnel, Précis Dalloz, Paris, 2004, p. 212.

${ }^{25}$ Kelsen, Hans. "Le contrôle de constitutionnalité des lois. Une étude comparative des Constitutions autrichienne et américaine", RFDC, No. 1, France, 1990, p. 17.

${ }^{26}$ KelSEN, HANS. "La garantie juridictionnelle de la constitution", RFDP, France, 1928, p. 14.

${ }^{27}$ Gahdoun, Pierre-Yves. La liberté contractuelle dans la jurisprudence du Conseil constitutionnel, Dalloz, Paris, 2008, p. 260.

${ }^{28}$ Cerda-Guzman, Carolina. Codification et constitutionnalisation, LGd, Paris, 2011, p. 27.

${ }^{29}$ Bergel, JeAn-Louis. Méthodologie juridique, Puf, Paris, 2001, p. 26.

${ }^{30}$ RIPERT, Georges. Les forces créatrices du droit, LGDJ, París, 1994, p. 74.

${ }^{31}$ Timsit, Gérard. Les noms de la loi, Puf, París, 1991, p. 27. 
Los líderes del positivismo de Weimar, ${ }^{32}$ Thoma, Anschutz, Kelsen o Radbruch, comparten el mismo postulado inspirado de la obra de Max Weber (1864-1920): $:^{33}$ el relativismo ético. ${ }^{34}$ En contravía de las doctrinas de derecho natural, el relativismo niega que sea posible emitir cualquier tipo de enunciado científico en materia de ética. Según el célebre sociólogo alemán, el conocimiento científico sólo puede versar sobre hechos, sobre un Sein cuya veracidad es empíricamente verificable, al contrario de lo que acontece con los juicios de valor, que pertenecen a la esfera del Sollen. Dado el abismo infranqueable entre el Sein y el Sollen, entre lo que es y lo que debe ser, el científico sólo puede pronunciarse sobre lo primero y no sobre lo segundo. En consecuencia, el ámbito de los valores, del Sollen, corresponde a la pura subjetividad.

Por ello no hay una idea de la justicia, sino muchas al tenor de las opiniones de unos y otros en un contexto dado. ${ }^{35}$ Se trata de lo que Weber denomina "la guerra de los dioses": lo que representa Dios para uno, será el diablo para el otro. Esta conclusión extraída de los límites epistemológicos del saber humano estaría confirmada, de creer a estos autores, por el estudio de los sistemas jurídicos del pasado o los extranjeros. La diversidad irreductible de los sistemas de valores clama por una decisión humana, una elección arbitraria por tal o cual sistema, sin que la ciencia pueda juzgar objetivamente sobre la legitimidad de la solución adoptada. Así, corresponderá de manera soberana al legislador definir qué es lícito, en ausencia de definición científica de lo que es justo. ${ }^{36}$ Tomado a la letra, los criterios de cientificidad de los positivistas llevan a ubicar en un estricto plan de igualdad todas las teorías políticas: $:^{37}$ la preferencia de la democracia sobre una monarquía e incluso una dictadura únicamente puede, así las cosas, resultar de una elección subjetiva (arbitraria), tal como lo admite reiteradamente Kelsen. ${ }^{38}$ Por lo anterior, los derechos humanos constituyen

\footnotetext{
${ }^{32}$ Como es bien sabido, la derrota de Alemania en la Primera Guerra Mundial determinó que su emperador fuese destronado en medio de una honda crisis nacional. En consecuencia, en enero de 1919, se convocó a elecciones para una Asamblea Constituyente, que redactaria la Constitución de Weimar. Formalmente, Alemania se convirtió en una democracia parlamentaria, respetuosa de los derechos y libertades ciudadanas. Sin embargo, el artículo 48 de ese texto dispuso que en caso de amenaza contra la seguridad del Estado, el presidente estaría autorizado para adoptar medidas de emergencia con fuerza de ley, paralizando y aboliendo el control político parlamentario. En 1933, Hitler se aprovechó del artículo 48 con las tristes consecuencias conocidas.

${ }^{33}$ Mesure, Sylvie y Renaut, Alain. La guerre des dieux. Essai sur la querelle des valeurs, Grasset, Paris, 1996.

${ }^{34}$ RadBRUCH, Gustavo. Relativismo y derecho, Bogotá, Universidad Externado, 2009, p. 18.

${ }^{35}$ Cfr. Kelsen, Hans. ¿Qué es la justicia?, Biblioteca de Ética, Filosofía del Derecho y Política, México, 2005.

${ }^{36}$ Ibid.

${ }^{37}$ Heuschung, Luc. État de droit, Rechtsstaat, Rule of Law, tesis publicada, Dalloz, París, 2002, p. 119.

${ }^{38}$ Véase, por ejemplo, Kelsen, Hans. ¿Qué es la Teoría Pura del Derecho?, Biblioteca de Ética, Filosofía del Derecho y Política, México, 2004. Sin embargo, se constatan en Kelsen y sobre todo en Radbruch deslizamientos sucesivos que, en nombre del relativismo ético, van en el sentido de una legitimación científica de la democracia.
} 
una restricción que la democracia ha tenido a bien aceptar por idealismo ${ }^{39}$ pero que a su turno podrá revertirse en cualquier instante. Las consecuencias de esta concepción van a ser reveladas con la experiencia austriaca y la de la República de Weimar.

\section{La experiencia de Austria}

Implementada por la Constitución de 1920, la Corte Constitucional austriaca representa, junto con las jurisdicciones creadas por las constituciones checoslovaca de 1920 y española de 1931, la primera auténtica aplicación del modelo kelseniano. Esta alta jurisdicción especializada está especialmente encargada del control de la constitucionalidad de las leyes votadas por las asambleas provinciales. A petición del gobierno federal, esta corte podía así declarar la anulación de los textos contrarios a la Constitución, al gozar sus decisiones del revestimiento de cosa juzgada. ${ }^{40}$ La historia de esta Corte, que contó con Hans Kelsen entre sus primeros miembros, fue agitada.

Una revisión constitucional de 1929 en un primer momento le arrebató su independencia, motivando el retiro del célebre jurista austriaco. Con posterioridad a diversas alteraciones, la Corte fue suprimida en 1938, víctima del nazismo, en una Austria ocupada por Alemania. Restablecida al final de la Segunda Guerra Mundial por la ley constitucional de 1945 y desde entonces oficialmente denominada Corte Constitucional Federal, este tribunal constituye el punto de partida de la generalización de las cortes constitucionales en Europa.

\section{La experiencia de la República de Weimar}

A medida que los peligros que rondaban la República de Weimar por el nazismo se hacian realidad, Thoma y Kelsen volvieron parcialmente sobre sus posiciones. En efecto, una cierta ambigüedad se insinúa en sus escritos; además, se manifiesta mediante el bosquejo de una materialización, si bien tímida e incoherente, del concepto de democracia. ${ }^{41}$ Sin embargo, la postura de los positivistas a propósito del papel y lugar de los derechos y libertades garantizados por la Constitución de Weimar desembocó en el más radical de los legalismos.

\footnotetext{
${ }^{39}$ Kelsen, Hans, como se citó en Heuschung, Luc. Op. cit., p. 121.

${ }^{40}$ Favoreau, Louis. Droit constitutionnel, Précis Dalloz, Paris, 2004, p. 213.

${ }^{41}$ En efecto, si en 1920 Kelsen afirma que los derechos humanos constituyen una "exigencia esencial de toda constitución democrática" - propósito que omitirá en la edición de 1929- vuelve a su punto de vista inicial en 1933, poco antes del fin trágico de Weimar. Anteriormente, ya había destacado la necesaria cohabitación de la mayoría con la minoria; no obstante, sin deducir alguna garantía en beneficio de ésta.
} 
El primer inciso del artículo 109 de esta Constitución ${ }^{42}$ dio lugar a auténticos problemas de interpretación: ¿Se trata de una verdadera norma jurídica, vinculante incluso para el legislador o, por el contrario, no es más que una simple directiva política con carácter puramente programático? En este debate, los positivistas tuvieron marcada tendencia a acordar más bien una altamente débil normatividad a las disposiciones de la segunda parte de la Constitución de Weimar, dedicada a los valores fundamentales de la nación alemana. Esta lectura extremamente prudente, entiéndase tímida, se justifica a los ojos de los positivistas por dos razones: la ambigüedad intrínseca de tales disposiciones y la identidad de aquel a quien debe aplicarse esta normatividad: el legislador elegido democráticamente.

Según los positivistas, únicamente una disposición constitucional clara que indique precisamente aquello a lo cual el legislador está constreñido constituye una norma jurídica. ${ }^{43} \mathrm{~A}$ la luz de este criterio técnico, los positivistas llegaron a pesar cada palabra, cada fragmento de frase para establecer su peso normativo. Habida cuenta de su escepticismo hacia el discurso sobre los valores, su dictamen en materia de valores constitucionales fue frecuentemente negativo: numerosos derechos fundamentales son "carentes de sentido y superfluos" (Leerlaufend und überflussig). Se trata de principios tan vagos e imprecisos que dan lugar a una innegable polisemia, la cual exige una interpretación restrictiva: ${ }^{44}$ los límites epistemológicos de la ciencia jurídica lo exigen así como el respeto que se debe a las competencias del legislador.

Cualquier otra solución sería a la vez arbitraria y antidemocrática, especialmente si correspondiese a un juez el dirimir entre sistemas de valores contradictorios. En síntesis, la Constitución de Weimar es, según los positivistas, ante todo un modo de organización del proceso democrático, más que un texto garante de los derechos y libertades del individuo que en su mayor parte "no valen gran cosa". ${ }^{45}$ De esta manera, la Constitución de Weimar se encuentra completamente a la merced del parlamento.

Revestido de soberanía, el legislador de Weimar podrá modificar cualquier contenido de la Constitución, tal como los derechos humanos. Plantear algo

\footnotetext{
${ }^{42}$ El artículo 109 inciso 1 dispone que "todos los alemanes son iguales ante la ley". [Citado: 23. Enero. 2016]. Disponible en: http://www.unav.es/constitucional/Materiales/Constitucion\%20de\%20Weimar\%20(1919).pdf

${ }^{43}$ Heuschling, Luc. Op cit., p. 119.

${ }^{44}$ En 1932, Thoma matizó algo su posición inicial, que en adelante le pareció demasiado tímida. En el momento en que integró más los derechos humanos en la definición de la democracia, trató de dar mayor significación jurídica a aquellos, optando, en caso de duda, por una interpretación jurídica amplia. Esta conversión no irá, sin embargo, demasiado lejos, debido a las premisas relativistas que mantiene. Es por ello que Thoma no cambió de posición frente a la naturaleza jurídica del artículo 109 inciso 1 de la Constitución de Weimar.

${ }^{45}$ Thoma, Richard, como se citó en Heuschung, Luc. Op. cit., p. 124.
} 
distinto sería desconocer la legalidad. De esta manera y por más que al pueblo le pese, nada ha de impedir que el legislador elegido democráticamente suprima, por ejemplo, las libertades individuales antes de barrenar la democracia misma. Sólo dos voces entre los positivistas se opusieron a esta visión: Walter Jellinek, quien consideró que el derecho de voto es para el Reichstag un límite implícito intocable, y Gustav Radbruch, quien afirmó en 1934, cuando ya era demasiado tarde, que "la democracia lo puede todo, salvo renunciar definitivamente a sí misma”. ${ }^{46}$ Esta amarga experiencia va a dejar su huella en el modelo jurídico de posguerra.

\section{La constitucionalización del derecho: una secuela de posguerra}

En Europa, con el desenlace del primer conflicto mundial así como el ascenso de los extremismos políticos y la necesidad de un intervencionismo estatal debido a las consecuencias económicas y sociales traumatizantes de la guerra, se verificó la posibilidad de que el legislador tuviese la deliberada voluntad de atentar contra las libertades públicas proclamadas por las leyes y por la tradición republicana. ${ }^{47} \mathrm{Al}$ entusiasmo de 1919 por el Volksstaat (Estado popular) sigue, en la generación de juristas alemanes de posguerra, una neta desilusión tras de la cual se constata una cierta desconfianza hacia el ideal rousseauniano de la ley como sempiterna expresión del pueblo.

No se trata de repudiar la democracia, sino de criticar una concepción específica de ella: la "decisionista-totalitaria". Así, los positivistas de Weimar fueron acusados de haber servido a los propósitos de Hitler mediante la concepción absolutista y omnipotente de la soberanía popular. ${ }^{48}$ Esta visión predicaba que el pueblo puede disponer sobre lo que sea sin que su decisión jamás pueda ser cuestionada, a tal punto que es al pueblo a quien corresponde establecer incuestionablemente lo que es justo e injusto. ${ }^{49}$ De esta manera se habría llegado a la asimilación vox populivox dei, calificada en la posguerra como una idolatría de la democracia. ${ }^{50}$

La controversia sobre el positivismo kelseniano en la posguerra es bien conocida tanto en Francia ${ }^{51}$ como en América Latina: ${ }^{52}$ algunos piensan detectar

\footnotetext{
46 "La démocratie peu faire tout, sauf renoncer définitivement à soi-même". RadBRUCH, Gustav. Op. cit., p. 105.

${ }^{47}$ Frangi, Marc. Constitution et droit privé, Economica, Paris, 1992, p. 8.

${ }^{48}$ De Jouvanel, Bertrand. Du pouvoir. Histoire naturelle de sa croissance, Hachette, Paris, 1972, p. 415.

${ }^{49}$ Heusching, Luc. Op. cit., p. 144.

${ }^{50} \mathrm{Cfr}$. Talmon, JaCob Leib. Les origines de la démocratie totalitaire, Calmann-Lévy, France, 1966.

51 "Dans un deuxième temps, Kelsen a justement renoncé à cette conception naïve [ingenua] et considère que la signification était seulement déterminée par le processus de l'interprétation." Troper, Michel. La théorie du droit, le droit, l'État, Puf, France, 2001, p. 15

${ }^{52}$ Correas, Óscar. "El otro Kelsen", en Nuevo Kelsen, Universidad Nacional Autónoma de México, México, 1989, p. 27.
} 
una evolución notable del pensamiento de Kelsen, quien se habría alineado, al menos al final de su obra, del lado de los realistas estadounidenses. ${ }^{53}$ De esta manera, habría "varios" Kelsen. ${ }^{54}$ Otros piensan que tal afirmación para nada corresponde con la realidad del maestro austríaco. ${ }^{55}$ Como quiera que sea, la obra de Kelsen no se deja aprehender fácilmente. A pesar de ello, en la posguerra el positivismo de Kelsen, Thoma o Anschütz fue puesto en la picota: tanto su relativismo como su hostilidad hacia la metafísica minaron el sustrato ético del derecho. La ciencia jurídica alemana de posguerra se alejó así de un positivismo formalista acusado de las peores barbaridades.

Según Gustav Radbruch, quien reniega en 1945 de su pasado de positivista y se convierte en defensor de un regreso al derecho natural, "El III Reich quebrantó [...] los derechos humanos más sagrados (vida, libertad, honor). [...] los déspotas de la dictadura de doce años le dieron múltiples formas legales a la dictadura y el crimen [...] El concepto de derecho establecido, el incuestionable positivismo dominante por décadas entre los juristas alemanes y su doctrina ley es ley, fueron inermes e impotentes frente a semejante injusticia en forma de ley". ${ }^{56}$ En adelante, serán los valores materiales o metajurídicos la base, es decir, el elemento primero del orden jurídico. Únicamente dentro del marco de tales valores los órganos democráticos podrán producir normas jurídicas. ${ }^{57}$

Esta nueva concepción marca el punto de partida del proceso de materialización y de jurisdiccionalización del derecho, ya que esos valores humanistas serán garantizados por el juez. En ese contexto, tiene lugar un "renacimiento" de la teoría del derecho natural, ${ }^{58}$ la cual ha marcado con su sello la jurisprudencia de la Corte Constitucional Federal alemana hasta nuestros días. ${ }^{59}$ La trágica experiencia del III Reich tendrá tal impacto en el espíritu de los redactores de la Ley Fundamental de 1949, que todas las dudas sobre el poder de los jueces se desvanecen ante la imperiosa necesidad de garantizar los derechos humanos contra los desvaríos no sólo del parlamento, sino incluso de un pueblo entero. ${ }^{60}$ La ruptura con la concepción democrática, así como con la herencia del positivismo de Weimar, es netamente perceptible en lo que concierne a

\footnotetext{
${ }^{53}$ Véase en tal sentido KeISEN, HAns. "Le contrôle de constitutionnalité des lois. Une étude comparative des Constitutions autrichienne et américaine", op. cit., p. $17 \mathrm{~s}$

${ }^{54}$ Gahdoun, PIerRe-Yves. "La liberté contractuelle dans la jurisprudence du Conseil constitutionnel", Dalloz, Paris, 2008, p. 171.

${ }^{55}$ Véase LeBen, ChaRLES. "Troper et Kelsen", Droits, France, 2003, p. 25.

${ }^{56}$ RadBRuCH, Gustav. Relativismo y derecho, Universidad Externado, Bogotá, 2009, p. 18.

${ }^{57}$ Heuschung, Luc. État de droit, Rechtsstaat, Rule of Law, tesis publicada, Dalloz, Paris, 2002, p. 145.

58 Kaufmann, Arthur. Filosofía del derecho, Universidad Externado, Bogotá, 1999, p. 75.

${ }^{59}$ Heuschling, Luc. Op. cit., p. 157.

${ }^{60}$ Ibidem, p. 143.
} 
la cuestión, tan vivamente debatida en esta época, del estatus jurídico de los derechos fundamentales y los límites materiales del poder de revisión. Cada uno de esos aspectos pone en evidencia los fundamentos de derecho natural del orden constitucional alemán edificado en 1949.

Igualmente en Francia luego de la Libération, las violaciones a los derechos fundamentales durante l'Occupation y el régime de Vichy, ${ }^{61}$ habiendo mostrado la falibilidad del poder legislativo y la necesidad de afirmar nuevamente los derechos humanos, ${ }^{62}$ motivó la promulgación de la Constitución francesa de 1946 (que instauró la IV République), la cual implementó una justicia constitucional. Adicionalmente, durante la posguerra las necesidades de la reconstrucción van a fortalecer el intervencionismo estatal en Francia. ${ }^{63}$ En consecuencia, el derecho constitucional ejerció una influencia indirecta y creciente sobre el derecho ordinario francés. Tal tendencia incluso se fortaleció con la Constitución de 1958, que instauró la V República francesa ${ }^{64}$ a pesar de los jueces ordinarios, leales al principio de la soberanía parlamentaria. ${ }^{65}$ En efecto, en la posguerra el legalismo contó con sus aliados, ya que el positivismo profirió su réplica.

Ya se verificó que Gustav Radbruch provocó una polémica hacia el final de la Segunda Guerra Mundial. Este expositivista estigmatizó el positivismo jurídico por ser, si no el responsable, al menos el cómplice objetivo de la perversión del derecho nazi. Los positivistas habrían no solamente descrito en un tono neutro el estado del derecho positivo tal como era, sino que igualmente habrían legitimado el orden en vigor, predicando el deber de obediencia a la ley. De esta manera, el espíritu legalista así definido constituye la esencia misma del positivismo; los dos términos en realidad designan una sola y misma concepción del derecho. ${ }^{66}$

\footnotetext{
${ }^{61}$ Frangi, Marc. Op. cit., p. 8.

${ }^{62} \mathrm{Cfr}$. Hourouebie, Fabrice. "Majorité et légalité dans l'Etat de droit. Des places respectives du juge et du représentant dans la démocratie constitutionnelle", Annales du droit de Louvain, No. 1-2, Bélgica, 2005, p. 49.

${ }^{63}$ Frangl, Marc. Constitution et droit privé, Economica, Paris, 1992, p. 9.

${ }^{64}$ Un año después de su instauración, la IV República francesa inició un acelerado proceso de crisis, fruto de variados factores, entre los cuales destacan la ausencia de mayoría parlamentaria, ruptura del tripartidismo, doble oposición al régimen (protagonizada por el general De Gaulle), o la crisis de investidura de los gobiernos. En 1958 se dio el golpe de fuerza militar y el Comité de Salud Pública de Argelia, que determina la renuncia del gobierno de ese entonces, y el regreso al poder de De Gaulle. El nuevo gobierno obtiene al poco el voto de la Ley Constitucional de 1958, que inspirará la Constitución francesa del 3 de junio de 1958, hoy en vigor. Véase Pactet, Pierre, Méun-Soucramanien, Ferdinand. Derecho Constitucional, Legis, Bogotá, 2011, p. 315.

${ }^{65}$ Por temor a la acusación de instaurar un "gobierno de los jueces" al tiempo que no es un órgano elegido democráticamente, el juez ordinario generalmente es reticente a abordar el problema de la constitucionalidad. Sobre esta actitud que en Francia ha evolucionado, véase Favoreau, Louls. "France, note sous C. cass. Ch. Crim", 25 avril 1985, Bogdan et Vuckovic, 1985, p. 169.

${ }^{66}$ Radbruch, Gustav. Relativismo y derecho, Universidad Externado, Bogotá, 2009, p. 18. Cfr. Perelman, Chaïm, Vander Elst, Raymond. Les notions à contenu variable en droit, Bruylant, Bruxelles, 1984. Perelman, Chaïm, Foriers, Paul. La motivation des décisions de justice, Bruylant, Bruxelles, 1978.
} 
Esta identidad es vigorosamente rechazada por numerosos defensores contemporáneos del positivismo, como Hart, Ross, M. Troper, H. Dreier, N. Hoerster, entre otros. ${ }^{67} \mathrm{Si}$ estos autores aceptan desde un punto de vista histórico que determinados juristas autodenominados positivistas han efectivamente contribuido a tal ideología o ética legalista, por el contrario rechazan tal reproche al positivismo desde el plan teórico. Según ellos, el auténtico positivista debe limitarse a describir los hechos absteniéndose de todo juzgamiento, negativo o positivo. Los legalistas serían en realidad falsos positivistas o, en otros términos, iusnaturalistas ocultos. ${ }^{68}$

En aras de salvar al auténtico positivismo, los positivistas de posguerra tienden a sacrificar -en general, de manera implícita- el ilustre linaje de los supuestamente positivistas de los siglos XIX y xx.69 Ahora bien, el costo de tal operación de deslastre lejos está de ser inocuo: así se pretende que el positivismo -el verdadero- sólo apareció recientemente en Europa y que en consecuencia constituye una teoría del derecho más bien joven que aún está pendiente de sometimiento a falsación, pues es inviable hacerlo reposar sobre la herencia de sus ancestros. Queda por verificar si el positivismo, en estricto sentido, tal como ha sido formulado en el siglo xx por Kelsen e incluso Hart, realmente escapa a las trampas del legalismo y si es capaz de fundamentar un concepto coherente del derecho.

Sobre tal punto, legítimamente se pueden alimentar serias dudas. Ahora bien, no es menos cierto que los nazis vituperaron el positivismo ${ }^{70}$ por su relativismo, su cobardía y su indiferencia hacia los valores en general (y a los del Volk, la sangre o la raza, entre otros) así como por su docilidad; pero también resulta innegable que los adláteres de Hitler aprovecharon esta mansedumbre

\footnotetext{
${ }^{67}$ Lo cual es igualmente predicable de la doctrina hispánica -Garcia, JuAn Antonio. lusmoralismo(s), Dworkin, Alexy, Nino, Legisprudencia.pe, 2014- y la doctrina colombiana. Véase TAMAYo, Javier. Manual de hermenéutica juridica, Diké, Bogotá, 2013, p. 67, a propósito del "positivismo ingenuo", para diferenciarlo del "positivismo científico"; LóPEZ, Diego. Teoría Impura del Derecho, Legis, Bogotá, 2009, pp. 119 y 145.

${ }^{68}$ Según los positivistas de posguerra, el legalismo debe lógicamente ser calificado como teoría del derecho natural: el elemento metajurídico se revelaria en el deber moral de obedecer la ley, importando poco que sea justa o injusta. ${ }^{69}$ Mientras que en el ámbito hispánico autores como J. García sostienen enfáticamente que las críticas al positivismo se basan en lecturas superficiales o maliciosas de la obra y pensamiento de Kelsen (v. gr. Iusmoralismo(s), Dworkin, Alexy, Nino), en Colombia, Diego López, en otra variante de la réplica positivista, ha sostenido que en realidad Kelsen ha sido mal interpretado en América Latina. Esta región es un "ambiente hermenéutico pobre" el cual -a diferencia de Europa o América del Norte - tiene acceso a una extremadamente pequeña parte de la obra del maestro de Viena. Véase López, Diego. Op. cit., pp. 119 y 145. Cfr. Herrera, Carlos Miguel. Actualité de Kelsen en France, LGDJ, Paris, 2001.

${ }^{70} \mathrm{Sin}$ embargo, debe reconocerse que las grandes figuras de la escuela positivista fueron perseguidas luego del ascenso al poder de Hitler, bien por razones raciales, bien por cuestionar al régimen. Esto motivó el retiro de otros. Bajo el impulso de Schmitt, Larenz o Lange, la nueva ciencia jurídica se libró a una crítica en regla del positivismo jurídico.
} 
sin vergüenza alguna, ya que fue útil a su causa. ${ }^{71}$ De hecho, se cuenta con otra prueba contundente de ello, así como de los problemas del legalismo.

En la carta enviada en 1940 por el presidente del Sénat de Vichy, Jules Jeanneney, al mariscal Pétain, en respuesta a la solicitud de la lista de los senadores judíos, escribió: "Desapruebo la ley sobre el estado de los judíos por todo lo que ella tiene de contrario a la Justicia, al respeto de la persona humana, a la tradición francesa, como también porque los alemanes nos la han impuesto. Ella es sin embargo la ley. Obediencia le es debida". ${ }^{72}$ Por lo anteriormente expuesto hoy se tiene que esta concepción legalista ha sido matizada por el modelo constitucional de posguerra.

\section{Más allá del iusnaturalismo y del iuspositivismo}

La extrema virulencia del debate entre naturalistas y positivistas verificada durante Weimar se ha mantenido en la posguerra. ${ }^{73}$ El gran balance de tal querella pareciera ser que ambas corrientes tienen gran responsabilidad en la permisión del auge del totalitarismo de entreguerras. Es por ello que un número creciente de autores explora una tercera vía, más allá de este dualismo hoy considerado reduccionista, maniqueo y estéril: ${ }^{74}$ en lugar de ubicar estas escuelas en un plano de antagonismo irreconciliable, se propone situarlas en un contexto de complementariedad. ${ }^{75}$

\footnotetext{
${ }^{11}$ Por otra parte, la doctrina jurídica nacionalsocialista traza un neto regreso a los "verdaderos" valores del derecho y predica un iusnaturalismo un tanto particular (superioridad racial, por ejemplo). Igualmente, buena parte de estos mismos iusnaturalistas que cantaron loas a Hitler, luego de 1945 se unieron a las acusaciones contra el positivismo como doctrina funcional al nazismo, clamando por la resurrección del iusnaturalismo, realidad histórica que igualmente desacredita a esta escuela. Sin embargo, tal constatación de ninguna manera exonera de responsabilidad al iuspositivismo: si bien es verdad que esta corriente lejos estuvo de ser la dominante luego del ascenso de Hitler a la dictadura, es igualmente cierto que durante Weimar la escuela positivista, a pesar de sus ideales democráticos, terminó legitimando la teoría del suicidio legal de la democracia gracias a su hostilidad a la metafisica, desprecio por la justicia y correspondiente servilismo a las decisiones políticas. Por ello, indudablemente los positivistas demócratas de Weimar tienen una responsabilidad al menos parcial frente al desastre totalitarista de la primera mitad del siglo xx en Europa.

72 "Je réprouve la loi sur le statut des Juifs pour tout ce qu'elle a de contraire à la Justice, au respect de la personne humaine, à la tradition française, comme aussi parce que les Allemands nous l'ont imposée. Elle est pourtant la loi. Obéissance lui est due." JeAnneney, Jules. Journal politique: septembre 1939-juillet 1942, France, 1972, p. 282.

${ }^{73}$ Véase BobBio, Norberto. "El Problema del Positivismo Jurídico", Fontamara, México, 2004, p. 68: "por jusnaturalismo entiendo la teoria de la superioridad del derecho natural sobre el derecho positivo; por positivismo jurídico la teoría de la exclusividad del derecho positivo. El jusnaturalismo es dualista; el positivismo jurídico, monista".

${ }^{74}$ Heuschling, Luc. Op. cit., p. 437-438.

${ }^{75}$ Radbruch habria sido el pionero de esta propuesta, al plantear la necesidad de implementar una justicia supralegal que corrigiese determinadas injusticias legales (véase su artículo "Injustice légale et droit supralégal", APD, France, 1995, p. 307). De esta manera, ha de privarse toda validez a las normas jurídicas evidente e intolerablemente injustas, mientras que por razones de seguridad jurídica ha de admitirse la eficacia de las normas tolerablemente injustas. Será primariamente el derecho constitucional, cuerpo supralegal pero al mismo tiempo
} 
Además, en una Europa en búsqueda de paz donde los parlamentos, lección de la historia del siglo $\mathrm{xx}$, han demostrado que pueden ser igualmente peligrosos para las libertades, la implantación del sistema kelseniano de justicia constitucional -evidentemente enmendado- se vuelve una de las primeras características de las democracias europeas: Italia en 1947, Alemania en 1949, Francia en 1958, Portugal en 1976, España en 1978 o Bélgica en 1980 lo adoptan sucesivamente. La imbricación entre justicia constitucional y democracia es particularmente neta en los casos de Portugal y España, quienes, al igual que Italia y Alemania antes, implementan un sistema de control de constitucionalidad al salir de periodos de dictadura. ${ }^{76}$ En todas esas experiencias se encuentran los principales componentes del modelo kelseniano, si bien con una evolución que se verifica con la superación del control formal de constitucionalidad de las leyes mediante un control material de constitucionalidad, lo cual conlleva que en adelante las leyes deben ser conformes con los principios y valores de las constituciones de posguerra: ${ }^{77}$ ya no basta que el trámite legislativo siga fielmente el procedimiento constitucional de elaboración de las leyes; también es imprescindible que el resultado sea conforme con la axiología constitucional.

Entre las funciones esenciales de las constituciones contemporáneas, se encuentra la organización del sistema normativo. Kelsen ha demostrado contundentemente cómo la Constitución regula el proceso de creación de normas. ${ }^{78}$ De esta manera, en el modelo europeo la reconstrucción de las fuentes del derecho alrededor del eje constitucional constituye la manifestación primera, y sin duda la menos cuestionada, ${ }^{79} \mathrm{del}$ proceso denominado "constitucionalización de las ramas del derecho”. Desde esta perspectiva, la regulación constitucional de las fuentes normativas va mucho más allá de la manera en que las normas jurídicas deben ser creadas (órganos, procedimientos).

La Constitución también establece, con un grado más o menos grande, según el caso, la determinación del contenido mismo de ciertas normas, especialmente prescribiendo o, al contrario, proscribiendo tal o cual contenido. Así las cosas, la incorporación en el texto constitucional de prescripciones relativas a las libertades y derechos fundamentales obliga, al menos de manera negativa, al

derecho positivo, el encargado de tal tarea: el primer criterio diferenciador entre injusticias tolerables e intolerables serán los derechos humanos.

${ }^{76}$ Tal y como aconteciera con Chile, primer pais latinoamericano en trasplantar este modelo europeo.

${ }^{77}$ Véase en tal sentido Uprimny, Rodrigo. "La Constitución de 1991 como constitución transformadora", en Stéphane Jost (Dir.), 20 años de la Constitución colombiana. Logros, retrocesos y agenda pendiente, Fundación Konrad Adenauer, Bogotá, 2012, p. 38.

${ }^{78}$ KelSen, Hans. Théorie générale des normes, PUF, París, 1996.

${ }^{79}$ Favoreau, Luols. Droit constitutionnel, Précis Dalloz, Paris, 2004, p. 136. 
legislador a abstenerse de proferir normas contrarias al texto constitucional, como la prohibición de cualquier forma de discriminación en función de la raza o la religión. ${ }^{80}$ Esta nueva realidad permite el reconocimiento del principio de constitucionalidad.

\section{El principio de constitucionalidad}

Éste significa ante todo un rebasamiento del principio de legalidad. También implica que la ley no se identifica con el derecho y que el reino del derecho exige una verificación de todas las normas jurídicas al tenor de la norma suprema del sistema nacional, que es la Constitución. ${ }^{81}$

En Europa occidental (en otras latitudes también), el control de constitucionalidad tiende a identificarse con un control jurisdiccional. Ahora bien, varios países europeos, por temor a una excesiva politización de la justicia, han optado por un control de constitucionalidad no jurisdiccional (Finlandia, Países Bajos, Luxemburgo). En Finlandia, el control se confía, de conformidad con la tradición del ombudsman, a un órgano parlamentario: la comisión constitucional. Igualmente, los poderes públicos tienen la posibilidad de demandar conceptos a la Corte Suprema. En los Países Bajos y Luxemburgo, la tarea corresponde a un organismo consultativo del gobierno: el Consejo de Estado.

En realidad, estos controles son muy diferentes en su espíritu de lo que hoy se designa con el término de control de constitucionalidad. La expresión parece en adelante implicar que, como lo había indicado Kelsen, el controlador no se confunda con el controlado, sino que sea un tercero imparcial.$^{82}$ El órgano que ejerce el control de constitucionalidad asume en principio la delicada misión jurídica de garantizar, mediante su interpretación de la Constitución, la supremacía de esta última, al tiempo que la adapta a las nuevas realidades sociales.

Si ello permite la reintroducción de la flexibilidad en las constituciones rígidas, debe igualmente reconocerse que el equilibrio es difícil de materializar, al tiempo que expone al juez a la crítica. El papel de este último es determinante y puede ubicarle en competencia con el legislador, y así con el poder de revisión constitucional. ${ }^{83}$ La inmensidad de la tarea explica tanto las esperanzas depositadas en tales instancias como las decepciones manifestadas a través de críticas, en ocasiones insultantes.

\footnotetext{
${ }^{80}$ Ibidem, p. 138.

${ }^{81}$ Grewe, Constance, Ruiz-Fabri, Hétène. Droits constitutionnels européens, Puf, París, 1995, p. 66.

${ }^{82}$ El eterno debate, ya planteado por Schmitt y Kelsen: ¿politización de la justicia, o juridización de la política? Muy probablemente ambas situaciones, en donde la segunda atenúa los riesgos de la primera.

${ }^{83}$ Ibidem, p. 67.
} 
En los Estados Unidos, el control de constitucionalidad ha sido consagrado por el juez. Es concebido como el instrumento que prácticamente permite asegurar la superioridad de la Constitución, consecuencia de la idea según la cual el juez debe no solamente aplicar la ley sino también el derecho. ${ }^{84}$ De esta manera, el juez norteamericano tiene la facultad de descartar aquellas normas, legislativas inclusive, en contradicción con la norma superior. Todo juez, antes de aplicar un texto, debe verificar tal conformidad. Este control es difuso, ya que lo practican todos los jueces. Su coherencia está garantizada por la existencia de una Corte Suprema que unifica la jurisprudencia.

Este modelo se ha expandido especialmente en los paises europeos influenciados por el derecho anglosajón o el sistema político estadounidense (Noruega, Suecia, Dinamarca, Islandia, Grecia). En este punto vale la pena recordar que algunos países latinoamericanos se adelantaron a sus homólogos europeos en el proceso de acogida del modelo estadounidense, Colombia incluida. ${ }^{85}$ Ahora bien, las diferencias al interior del grupo europeo de influencia estadounidense son sensibles. Conciernen a las modalidades del control, que son de importancia cuantitativa y cualitativa, donde emerge como noción esencial la de los derechos fundamentales.

Este término, utilizado ocasionalmente en derecho anglosajón (fundamental rights), figura explícitamente en la Ley Fundamental alemana de $1949 ; ;^{86}$ igualmente, esta expresión ha sido recogida tanto por la Corte de Justicia de las Comunidades Europeas como por la Corte Europea de Derechos Humanos para inscribirse en las Constituciones portuguesa de 1976 y española de 1978,

\footnotetext{
${ }^{84}$ Véase el fallo Marbury vs. Madison (1803), cuyo "magistrado ponente" fue el celebérrimo juez John Marshall: "0 bien, la Constitución es una ley superior, no enmendable por medios ordinarios, o está al mismo nivel que la legislación ordinaria y, como otras leyes, es enmendable cuando a la legislatura le parezca. Si la primera parte de esta alternativa es cierta, entonces una ley contraria a la Constitución no es derecho; si la última parte es la correcta, entonces las constituciones escritas son intentos absurdos, por parte del pueblo, de limitar un poder que por su propia naturaleza es ilimitable... la ley repugnante a la Constitución es nula".

${ }^{85}$ En efecto, y sin ánimo de exhaustividad, se tiene que el modelo estadounidense fue acogido por Argentina (1887), mediante el caso "Sojo" y "Viuda de Elotorno vs. Municipalidad Buenos Aires", o Venezuela (1893), así como Colombia, mediante la reforma constitucional de 1910, que instituyó la acción pública de inconstitucionalidad, o México (1917). Es por ello que en el esquema constitucional colombiano contemporáneo aún quedan huellas directas de la influencia estadounidense, como lo demuestra el ejemplo del control difuso y la excepción de inconstitucionalidad, la cual sin embargo se ejerce con extrema timidez por parte del juez ordinario colombiano, por no decir que ha sido prácticamente ineficaz en nuestro ordenamiento, debido a la crítica del gobierno de los jueces

${ }^{86} \mathrm{Nada}$ de raro tiene tal constatación, si se tiene presente que el constituyente alemán de 1949 también siguió otra recomendación de Radbruch: "Para llevar a cabo la renovación del derecho se requiere un elevado Tribunal [...] Sólo un Tribunal semejante puede garantizar realmente la efectividad de los derechos humanos y civiles de nuestras constituciones [...] Modelo para un tribunal superior alemán debe ser la Supreme Court, la más elevada corte de Estados Unidos, el más poderoso tribunal que conoce la tierra [...] En su seno han ocurrido los grandes cambios en la concepción americana del derecho". RadBRUCH, Gustavo. Relativismo y derecho, Universidad Externado, Bogotá, 2009, p. 21.
} 
así como en el proyecto francés de revisión constitucional de 1990, proclive a ampliar las facultades del Conseil constitutionnel. ${ }^{87}$

La noción de derechos fundamentales constituye hoy una referencia prácticamente común en la doctrina constitucional europea ${ }^{88}$ a pesar de la variedad de las apelaciones del derecho positivo o de las doctrinas nacionales: derechos (Bélgica, ${ }^{89}$ Luxemburgo, Irlanda, Gran Bretaña, Noruega), derechos de libertad (Dinamarca, Italia), derechos inviolables (Italia), derechos constitucionalmente garantizados (Austria, Suiza), libertades y derechos fundamentales (Suecia), derechos humanos (Noruega, Finlandia). De las anteriores maneras se designa un conjunto de derechos reconocidos y garantizados por normas en general constitucionales en contra del Estado y al menos en ocasiones también contra los particulares. ${ }^{90}$

Según Favoreau, ${ }^{91}$ el verdadero cambio provocado por la constitucionalización radica en el giro del orden jurídico alrededor de un nuevo eje: la constitucionalidad, que al mismo tiempo conlleva el abandono del antiguo eje (la legalidad), la cual es en adelante un simple componente de la constitucionalidad. En efecto, ahora es la constitucionalidad la garante del contenido esencial de los derechos fundamentales y no la legalidad, ya que su respeto, a partir de ahora, se confía al juez constitucional. Esto explicaría también la disminución de la importancia y del interés de los principios generales del derecho, en beneficio de los principios y valores constitucionales, cuestión también ligada al cambio de estatus de la legalidad.

En efecto, el control de constitucionalidad de las leyes funcionaría sobre un modo binario: la norma cuestionada o será conforme con la constitución, o no lo será. Ahora bien, al margen de esta alternativa un tanto estrecha, se ha desarrollado en Francia la técnica de las réserves d'interprétation, la cual permite al juez constitucional dejar su impronta así como sus interpretaciones más allá de la simple confección de la ley. ${ }^{92} \mathrm{El}$ derecho de contratos no debe evidentemente escapar a este esquema. Así, cuando el Conseil constitutionnel ejerce el control de constitucionalidad de las leyes, lógicamente se encuentra ante las alternativas, sea de censura sea la declaración de conformidad.

\footnotetext{
${ }^{87}$ Sobre las reformas a la Constitución de la V República francesa, véase Pactet, Pierre, Méln-Soucramanien, Ferdinand. Op. cit., p. 333.

${ }^{88}$ Favoreau, Luols. Op. cit., 1990, p. 81.

${ }^{89}$ Más precisamente Droits des Belges, igualmente predicable para el caso de Luxemburgo.

${ }^{90}$ Grewe, Constance, Rulz-Fabri, Hélène. Droits constitutionnels européens, Puf, París, 1995, p. 107.

${ }^{91}$ Favoreau, Luols. Droit constitutionnel, Précis Dalloz, Paris, 2004, p. 321.

${ }^{92}$ VIALA, AleXAndRE. "Les réserves d'interprétation dans la jurisprudence du Conseil constitutionnel", LGDJ, París, 1999, p. 17.
} 
Frente a esta alternativa (sí o no) un tanto rígida, se introduce una "tercera vía decisional": un "Sí, pero...". ${ }^{93}$ Se trata de la reserva de interpretación, por la cual el Conseil constitutionnel no interfiere con la voluntad del legislador, pero sí orienta la interpretación de las autoridades administrativas o la del juez ordinario, ${ }^{94}$ indicando los sentidos constitucionalmente inadecuados 0 permitidos de los textos normativos examinados. Desde luego, tal esquema es homólogo a las sentencias de exequibilidad condicionada de la Corte Constitucional colombiana.

\section{Conclusión}

La presentación de la ley como la expresión de la voluntad general hoy exige ser corregida; la ley es en adelante cuestionable: la norma legal votada por el Parlamento o Congreso es susceptible de un eventual control jurisdiccional de constitucionalidad. Así el Conseil constitutionnel francés ha llegado a la conclusión fundamental de que la ley "sólo expresa la voluntad general dentro del respeto a la Constitución". ${ }^{95}$ En adelante, la legalidad sólo debe ser concebida como la implementación de la constitucionalidad, de la cual no es más que uno de sus componentes. ${ }^{96}$ En consecuencia, el juez constitucional generalmente disfruta de un papel considerable en materia de interpretación de la Constitución. Es él quien da todo su sentido al texto constitucional y le insufla vida. Por supuesto, en vista de la nueva realidad, se le reprocha el ir demasiado lejos, al punto de imponer su propia visión de la realidad, desplazando así la voluntad del constituyente. ${ }^{97}$

La constitucionalización ha sido objeto de estigmas tales como el hiperconstitucionalismo, el panconstitucionalismo, o el todo-constitucional, entre otras derivaciones. En el fondo, buena parte de las críticas y temores son resultado de malentendidos o posiciones extremadamente radicales. ${ }^{98}$ La Constitución como norma jurídica superior para nada significa un remplazo de las reglas de derecho ordinarias por normas constitucionales: simplemente, la constitucionalidad se convierte en un imperativo del orden jurídico aplicable a la totalidad de sectores cubiertos por éste, y susceptible de influenciarle en un determinado número de aspectos.

\footnotetext{
${ }^{93}$ Gahdoun, PierRe-Yves. Op. cit., p. 271.

${ }^{94}$ Viala, AleXandRe. Op. cit., p. 64.

95 "La loi n'exprime la volonté générale que dans le respect de la Constitution." France, Conseil Constitutionnel, Décision No. 85-197 DC du 23 août 1985, GD No. 38.

${ }^{96}$ Favoreau, Luols. "Légalité et constitutionnalité", Les Cahiers du Conseil constitutionnel, France, 1997, p. 73 s.

${ }^{97}$ Favoreau, Luols. Droit constitutionnel, Précis Dalloz, Paris, 2004, p. 249.

${ }^{98}$ Ibidem, p. 320.
} 
La expansión de la constitucionalidad no se acompaña por una limpieza completa del orden jurídico, ya que en la mayoría de ocasiones el juez constitucional va a constitucionalizar lo que la doctrina italiana acostumbra denominar el derecho viviente, esto es, las soluciones que ya adoptó en derecho positivo particularmente el juez ordinario o administrativo. Esta consolidación del derecho viviente tiende a reforzar la posición del juez frente al legislador. Cualquier juez digno de tal nombre tiene en cuenta, cuando elabora sus decisiones, la situación social y política. De esta manera, el juez ordinario, particularmente si hay carencia de la ley o bien si varios principios fundamentales se enfrentan, se ve llamado a dirimir un conflicto entre normas superiores tal y como lo hace el juez constitucional, conciliando -o reconciliando- los principios en contradicción mediante la búsqueda de una coherencia común.

La imposibilidad antaño impuesta al juez ordinario de emplear la Constitución para contrarrestar los efectos perversos de la ley misma, o de la aplicación de la ley, lo ha conducido a secretar un "derecho fundamental de sustitución”99 bajo la forma de principios generales del derecho, cuyas soluciones son en ocasiones cercanas a las del juez constitucional. Si en Francia, otrora bastión del legicentrismo, determinados principios identificados por el Conseil constitutionnel ya habían sido afirmados por el juez ordinario con anterioridad, lo mismo se puede afirmar de las relaciones entre principios constitucionales y principios generales del derecho en Colombia y probablemente el resto de América Latina. De esta manera, lejos de ser opuestos o antinómicos, derecho constitucional y derecho ordinario pueden ser por el contrario plenamente cercanos ${ }^{100}$ gracias a los principios comunes que les rodean. Así, los principios fundamentales son susceptibles de aplicarse, no sólo en la ausencia de toda ley (lagunas jurídicas), sino también a la hora de interpretar las leyes mismas. 